\title{
The Spine or the Heart: The University of Jos in Search of a Library Building Model
}

The University of Jos, Nigeria, recently considered the spine library building concept (also called linear library or continuum) about which very little appears to be known. This design was subsequently not adopted by the university for the reasons given.

\section{$\mathrm{T}$} HE DISQUIETING, if perennial, situation observable in academic libraries and articulated in the following random excerpts engaged the attention of the administration of the University of Jos as it searched for a building model to house its library:

The hard facts are that research libraries invest very substantial funds to purchase books and journals that are rarely, or never, called for as well as equally large sums to construct and maintain buildings designed to make accessible quickly titles that are no longer either useful or sought by their clienteles. ${ }^{1}$

The in-coming Secretary of the (British) Library Association ... feels there is under-use of library facilities in higher education even in term time. ... .

A reference library was established but its exploitation remained another matter. . . . Are the periodicals there merely to gather dust and provide visual decorations for the shelves? 3

Meanwhile, librarians have been working to improve "access" to their institutions and resources. They have been trying to do a better job of letting people-especially the non-user-know what libraries have to offer. ${ }^{4}$

Thus, use of the resources and facilities to be provided by the University of Jos Library was to determine both the type and shape of its building as well as its internal organization. Indeed, our preoccupation with ensuring that maximum use would be made of the library led us to state in our subsequent brief

B. U. Nwafor is university librarian, University of Jos, Nigeria. for the architects that while the university library "exists to provide materials and facilities which enhance the achievement of the teaching and research objectives of its parent University, its main focus, however, centres not so much on the number of materials, print and non-print, it stocks (important though this is) as in its concern to ensure in a cost-benefit context, a high degree of (a) relevance of the acquired materials to the needs of the University, and (b) use made of these materials." Or new library building should thus deliberately encourage, induce, and advance the materialization of the above goals.

We were, of course, familiar with the famous statement that "the library is the heart of the university," a statement that, in real life, seems to be no more than a platitude or, at best, one that describes what ought to have been rather than what is. For many universities the library is seen by some teaching faculty and many students as something on the periphery of their academic programs, something one occasionally refers to. It remains to be appreciated as an integral part of the total academic effort.

We were also aware that most briefs prepared by academic librarians for their architects included the specification that the building be "centrally located" on campus. However, while this "commandment" is generally obeyed, future developments on campus have often pushed the physically centralized library to the perimeter of the university site.

There were two other factors we had to 
take note of as we considered a building model for our library. The first would become apparent from the one-man dialogue author Chinua Achebe once had with himself. "What do African intellectuals read?" he had asked. "The temptation is indeed strong to answer that question in one word: nothing . . .," he replied. "The habit of reading. . . is . . . important, for if it were . . . strongly developed in our intellectuals some of them at least would find the time. But the habit is simply not there."5 As with the intellectuals, so also with the students, only much worse. The library service we were planning was, in effect, for a community of which a reasonable percentage lacked library literacy.

For the literate ones, observations have shown that, like library users in other parts of the world, they prefer their library to be close to them, hence the existence of departmental libraries. On the other hand, the reaction of university librarians to departmental libraries is well known. On many campuses the issue of whether the central university library should coexist with departmental libraries has created strains in the relationship between the university librarian on the one hand and the deans of faculties and heads of departments on the other. We hoped that our future library would be unifying rather than divisive in its orientation. It should appeal to both the user and nonuser and as much as possible have built into it something that makes those for whose well-being it exists not want to ignore it. It should, through its careful conception and possible uniqueness, positively induce the university community to use its resources.

\section{Library Organizational Models}

Three alternatives for the physical organization of an academic library exist, namely:

1. Centralized-in which there will be only one central library serving the entire institution.

2. Decentralized -in which a central library exists side by side with autonomous or semiautonomous faculty/departmental libraries, or in which autonomous faculty/ departmental libraries only exist.

3. Part-Centralized and Part-Decentralized - in which a central library administers the departmental libraries that serve largely as service points.
The advantages and disadvantages of the various alternatives have been recorded in the professional press and are summarized here:

1. Centralized libraries almost always invite, with the expansion of their parent institutions, justified need for departmental libraries with their attendant management problems.

2. The fully decentralized system fragments the institution's library resources and is economically less acceptable than the centralized.

3. The part-centralized alternative retains all the characteristics of a compromise solution.

However, based on our stated objectives, which are underscored by easy accessibility to library resources and facilities for the reader and an administrative model that is not very expensive to operate, the third of the alternatives above seems to be closest to meeting our needs.

\section{Profile}

Our search for a library building plan began in 1976/77. The university became autonomous the previous year after existing as a campus of the University of Ibadan since 1971. Comprising nine faculties (including arts, social sciences, natural sciences, environmental sciences, medical sciences, education, continuing education, and law), with more than 35 departments distributed almost equally between its two campuses located five kilometers apart, the University of Jos enjoys the dubious distinction of being the only one of its kind in Nigeria known to be operating from a motley of buildings some of which must have served, before their acquisition by the university, as warehouses. The library on the township campus is housed in one of these buildings whose total area measures roughly 1,040 square meters $(11,232$ GASF). In 1978, a branch library was built on the Bauchi Road Campus. In 1980, these two libraries contained 52,000 volumes of books and bound journals, subscribed to 1,400 current serials, accommodated 340 readers drawn from a student (including postgraduates) and staff population of 2,700 and 300 respectively, and were manned by some 60 members of staff, 7 of whom were professionally qualified. 


\section{Team Planning}

It should be stressed that all the available professional staff of the library (then numbering four) were from the start involved in the exercise of choosing a building model. In June 1977, the National Universities Commission (NUC)* published its Standards Guide for Universities, a voluminous document, since twice updated, which was to serve as a "bible" for our university planners. Well before publication of the Guide, the university had set up a committee on which the university librarian served and that was charged with planning the physical development of both temporary and permanent sites. At about the same time, the NUC appointed a team of consultants to prepare a master plan for the physical development of the University of Jos.

The consultants, code-named JUPCON (Jos University Planning Consultants) consisted of experts drawn mostly from Denmark, where they had designed the architectural award-winning University of Odense. It was natural that the basic concepts underlying their plan for the University of Odense would influence their thoughts about Jos.

A key proposal of the University of Jos physical masterplan is that the University buildings shall incorporate a "Spine" of two, three or four storey buildings, roughly in a straight line running east and west, and linked by an important pedestrian path. The Spine would be flanked to the north and south by lower buildings serving the main academic units. The Spine itself will incorporate common services. ${ }^{6}$

"The University of Jos Physical Master Plan 4" further elaborated that "the Spine building contains administration, especially faculty administration, library, and reading rooms, canteens and common rooms, and common teaching facilities, especially classrooms."

\section{A Novel Concept}

The university library's first reaction to the novel idea of a library on a spine was not any

*The Nigerian equivalent of the British University Grants Committee, the NUC is a government agency responsible for the funding, overseeing, and coordination of the development of all Nigerian universities. more or less predictable than that of the University of Cape Town's library in South Africa (another library, we were to learn later, patterned after this most unconventional principle), when the concept was first introduced. Wrote the librarian, Ms. Taylor: "When the idea of this type of development was first suggested to me, I was not very sympathetically inclined towards it. I might almost say that I was appalled by the thought because I had been brought up, as we all are, on the concept of a central library. . . . ${ }^{7}$ In one of my communications with our ViceChancellor on the subject I was to write in this vein ". . . I have never worked in such a building, have never seen a librarian who has and could only find scanty references to it in the literature. ...."

The library staff spent time from then on literally combing the professional press and making inquiries near and far. In this respect, the bibliographic assistance Mike Wise of the College of Librarianship Wales Library and F. J. E. Hurst of the New University of Ulster Library gave to us proved invaluable. On the other hand, our inquiries to the libraries of the (British) Library Association and the American Library Association yielded no results from the former and the following excerpt from the latter: "My assistants and I have done some checking of our holdings (on linear or spine libraries) and can find nothing at all using either of these terms. Perhaps we are dealing with a difference in terminology-these are simply not terms which strike familiar chords with us. . .."8 After further clarification was provided by us, the ALA librarian wrote back to the effect that "none of our staff in Headquarters including those involved with library buildings and with academic libraries have seen situations in which the diagram you provided has been applied."

Yet according to Taylor, the spine library "was not an entirely new concept. I think the idea had been first formulated in Germany, with the planning of two new German universities, one at Bochum and one at Bielefeld." On the Continent, the phrase used to describe the concept is library continuum; the University of Cape Town claims to have first used the expression linear library for the same concept; whereas the term library spine is traced to the New University of Ulster Li- 
brary, another library building modeled after the principle.

\section{The SPINE Library}

The spine library system has been described in several ways by the very few people who have had to work in one. Terms such as "ingenious and unconventional," "an enormously long building," "a plan based on the principle of providing a maximum service to readers at a minimum cost," " "a logical answer to the problem of decentralization, while at the same time preserving a central control and a library which is virtually under one roof," 10 "decentralization without fragmentation," 11 "a library which from the start would be decentralized without being broken into separate buildings," 12 have been used to describe the linear library.

A description of the concept has been translated from the original brief used for the University of Bielefeld Library: "The library system forms a unit, but will physically not be contained in one central building. The bookstock will rather be centralized according to subjects and will be housed within the faculties. The administration will be central and bibliographical tools necessary for its information and co-ordination will be with the administration. The most important problem is to achieve the functional unity of the decentralized bookstocks of the faculties."13

Seen from the perspective of the usual organization of academic libraries on the Continent on departmental or institute basis, the library continuum appears to be a movement towards the American and English ideal of a central library. "The philosophy was an attempt to resolve the perennial struggle which occurs in any university library where the teaching department wishes to have the books as near as possible to the area where the teaching is done while the library wishes to keep the books all together so that they form one unified whole."14

At this point it should be stated that both the University of Jos and the NUC gradually felt convinced about the advantages of the spine concept as applied to the physical planning of the university and, consequently, decided to adopt it for its master plan. The issue of the location of the library on the spine was also adopted, but in principle only. To meet the planning program of the university, it was expedient that this action be taken while the search for additional information on spine libraries continued.

Meanwhile, in the university master plan, the library would occupy two floors (first and second levels) of the spine, an "enormously long building" of about 800 meters ( 880 yards) that did not need to be one continuous building and did not need a width uniform throughout its length. The library collection would be distributed in such a way that materials relevant to the needs of any given faculty would be concentrated around the point where the flanking faculty building meets the spine. The library administration and processing departments would be located midway along the spine. General reference books, bibliographies, indexing and abstracting journals and other general periodicals, the reserve and special collections, and the union catalog would also be located around here. The library would be organized on subject division basis, using the faculty as the unit for this arrangement. Thus, specialized reference books and monographs, indexing, abstracting and other journals, AV materials, etc., would be congregated at the subject libraries, which would be manned by subject librarians whose main assignments would be fourfold: namely,

1. to act as liaison with the faculties and monitor the nature, scope, and direction of their academic programs;

2 . to coordinate the collection development efforts in the relevant discipline(s);

3. to offer bibliographic and reference services in the relevant discipline(s); and

4. to offer user education programs. One or two loan desks and manned entrances to the faculty buildings were proposed. It was hoped that at the first opportunity, certain operations and procedures, including the circulation system, would become computerized. A COM catalog was considered imperative, as was an internal system of communication. A conveyor belt was also thought desirable.

Against the background of the Jos proposal, the advantages and disadvantages of the spine library will be discussed.

\section{Disadvantages \\ Administrative Problems}

Cape Town University's librarian readily 
admits that the linear library "brings with it a number of administrative problems." Indeed, our director of planning also concedes that the "administration of linear buildings presents unusual problems." And a colleague once teased, after listening to my description of how a spine library operates: "It seems to me you would not only need a conveyor belt but motorized wheel chairs for your staff!" The problem of long distances is real, although modern communications technology can ameliorate it to some extent. However, the need for a conveyor belt in a linear library is not any more or less justifiable than the need for elevators, hoists, and escalators in a vertical counterpart.

Another administrative problem foreseen in a library continuum is the wide dispersal of staff who may, because of their location in and close association with the teaching faculty, have to divide their loyalties between the dean of the faculty and the university librarian.

\section{Multiple Access Points}

The provision of multiple entrances into the faculty buildings from the library raises security problems, and, if they are to be staffed, extra cost problems. Advocates of the spine library, however, point out that if a central library were to exist side by side with departmental libraries, as is often the case, there would have been "multiple entrances" to care for. They add that if through the provision of additional entrances, "access" to library resources would be encouraged, this extra cost is justified.

\section{Noise Factor}

As the spine would serve as the main nonvehicular traffic route of the campus, this would distract library users located on the route, especially if the library were to occupy the ground-floor buildings of the spine. And even when the library is located on a floor other than the ground one, it is feared that as readers moved from one end of the continuum library to the other in search of needed materials, they would walk across reading areas, again disturbing readers. In any case, noise or other pollution could always originate from the neighboring departments on other floors, e.g., cafeteria, classrooms, etc., which would share the spine with the library. To these observations, it is countered that careful planning and utilization of modern acoustical techniques and materials could minimize, if not totally solve the problem.

\section{Duplication of Materials \\ and Catering for the \\ Interdisciplinary Reader}

The readers thought to be least favored by the linear library are those with interdisciplinary interests such as forensic or social medicine, educational psychology, or sociology of education; equally, undergraduates in institutions where they are required to take courses of a liberal arts nature. Worse, it is feared that the truncation of the library into "departments" may lead the undergraduate student, especially, into mistaking the resources of his small departmental library for the entire library resources of the institution.

To the first observation, it should be stated that the interests of the interdisciplinary reader have never been fully met by any library building model. For his convenience, a certain degree of duplication of resources is imperative. Otherwise, the reader simply has to move from one section of the library to the other. Worse, in a large campus with the conventional central library and a chain of departmental libraries, he would need to move from one departmental library to the other. He might even require a map of the campus to be able to locate the libraries.

An interesting feature of a campus planned on the spine principle is that possible affinities that may exist are considered as one faculty building and located next to the other. With this prior careful consideration and multiple points of entry to the library, frequent movement of readers along the length of the library would be minimized.

With regard to the interests of the undergraduate students, it is hoped that the provision of a central reserve collection (with its known disadvantages) would go some way in mitigating problems. Beyond that, a teaching method on campus that emphasizes the importance of information accessing skills on the one hand, and an effective library user education program on the other hand, will together ensure that students do not confine themselves to the use of their departmental libraries only. 


\section{Future Expansion}

Were the library to be located on any floor(s), excluding the ground floor, the problem of future expansion would indeed be serious. Wrote Hurst, "If library is on top floor, one cannot extend at either end unless there is further extension of the floor below (on the ground floor). . . . One would not be able to introduce compactus-type storage. ..." It is thus thought wise for the library to occupy the ground floor and preferably be linked by covered walkways to the faculty buildings at the first instance. This would allow for future lateral expansion. In the University of Jos master plan, certain spaces were reserved for the future growth of the library, but there was no certainty that those places would correspond with the points on the spine where the pressure for expansion would most be felt.

That said, it is important at the initial stage to determine, insofar as possible, the ultimate space needs of various units of the library. If, however, the principle of the selfrenewing ${ }^{15}$ or zero-growth library guides the planning of the library, then the question of the future expansion of the library would cease to be an issue. Proponents of the spine library point out that one of its major strengths lies in its adaptability to expansion as enrollment and/or collections grow.

Finally, it should also be stated that the initial logic guiding the configuration of faculty buildings becomes disrupted whenever a new faculty building is added and the spine (with the library) correspondingly extended.

\section{Costs}

Invariably, the first reaction of an administrator presented with the spine library building focuses on its cost: the manning of each departmental library by both security staff and subject librarians; the use of possibly more than one loan desk; the need for multiple catalogs; the distance to be covered in administering the extremely long building; etc. However, in respect to staff costs, a librarian operating a linear library observed: "Staffing - well, this depends on the services you offer. We have fewer staff than other university libraries and still function effectively. ..." The linear library represents "a plan based on the principle of providing a maximum service to readers at a minimum cost." In any case, if the spine library is appreciated for what it is - that is, a preferred alternative to having a central library as well as separate departmental libraries - its operating costs may not be more than those of both the central library and the departmental libraries, which together may not provide as effective library service as the spine library.

\section{Advantages}

The advantages of the spine library are:

1. User convenience - it locates the materials close to the user (and nonuser) and makes the need for the usual departmental libraries redundant.

2. It adroitly locates the subject librarian in both the library and the teaching department at the same time. If he pulls his weight, his acceptability as a colleague of the teaching faculty would be taken for granted and the issue of academic status solved.

3 . The spine library retains most of the merits and economies of a centralized library administration. It combines the best advantages of the centralized and decentralized library systems.

4. It ensures that the library remains physically and, it is hoped, intellectually at the heart of the institution.

5. At Jos, its arrangement is particularly ideal for the practicalization of the "teaching library concept," ${ }^{18}$ which is the basis for the organization of our library.

6. Finally, in the event of a disaster such as a fire, the linear has easier egress than a central library.

\section{The CounciL's Committee}

True, the advantages of the spine library are many, but its disadvantages cannot be ignored either. Indeed, it is the nearbalancing of its pros and cons that made the Council of the University of Jos decide to appoint a committee in January 1978 to study the issue in greater detail.

It was of utmost importance that all information about this type of library should be available, as it would be wrong and costly to adopt (or not adopt) the concept in the absence of essential information.

It was against this background that the council's committee decided to seek "direct 
evidence from operational spine libraries," an exercise that took three members of the committee, including the university librarian, to the University of Odense, Denmark, and the New University of Ulster, Coleraine, Northern Ireland, from November 14-23, 1978.

Perhaps it should be recalled here that before this visit the university librarian was opportuned to visit for six weeks, between July and August 1978, a number of academic libraries and related institutions in the United States (including the libraries of Ohio State University, University of Chicago, Northwestern University, Harvard University, MIT, New York Public Library, University of California campuses at Berkeley, Los Angeles, and San Diego, Hampshire College, ALA Headquarters, the Library of Congress, the Association of Research Libraries, etc.). The United States International Communication Agency (USICA) had sponsored the trip with an expressed aim to "observe some U.S. academic libraries and related institutions with particular reference to the specific areas of library architecture, administration and automation, and meet with professional colleagues." This trip made it possible to meet, among others, Ralph Ellsworth and Ellsworth Mason, to discuss academic library building planning. The linear library concept was discussed with many of these colleagues, several of whom appeared not to have heard of it earlier. Their reactions to it were predictable - ranging from descriptions as "a disaster" to "excellent and radical." The more experienced librarians were more negatively inclined than younger colleagues. Ultimately, the university benefited immensely from all the opinions we received.

Before the U.S. visit, I had another opportunity to visit a number of university libraries and related institutions in the U.K. (including the Universities of Surrey, Sussex, East Anglia, Nottingham, SCONUL office, the Library Association Library, etc.). Again, I used the occasion of the trip to seek the reactions of colleagues to this library system and benefited from their counseling.

\section{THE VISIT}

The three-member team spent roughly a day and a half both at Odense and Coleraine observing the operation of the libraries and holding discussions with both the library staff and the users.

The library of the University of Odense, completed about four years ago, occupied the first/top floor of the narrow spine and small parts of the ground floor below it, where the main entrance, lending counter, some administrative and work rooms are located. Covering a length of about 200 meters (220 yards), it has two subsidiary access points which go directly to the faculty buildings. These access points were little used but to justify location of staff by them, other functions such as duplication and photocopying and periodicals display are located there.

Neither the library staff nor the academics interviewed seemed positively pleased with the system: there was an impression of "making the best of it." It was further observed that few institute (departmental) libraries continued to exist side by side with the spine library. The University of Odense was planned for a student population of 4,400 .

The first phase of the New University of Ulster (NUU) at Coleraine, Northern Ireland, was completed in 1968 and contained a library built on conventional lines. Today, it serves as the Education Library. Five years later and some 228.5 meters ( 250 yards) away from phase one building (owing to site defects, we were informed), the phase two buildings, with a "long narrow library 130 yards (118.8 meters) in length," were erected. This library occupies the second/top floor at a higher level than any of the adjacent faculty buildings. There were two subsidiary access points to the faculty buildings that were kept permanently locked and, therefore, not in use. Most of the library operations were computerized. Unlike Odense, there were no departmental libraries on the campus (planned for about 6,000 students by 1980: the ultimate size could not be foreseen), and both the library staff and the users seemed to be pleased with their two libraries, which were apparently more heavily used than those of Odense. The second-floor location of the library was, however, not altogether satisfactory for some library staff, a fact shared by the librarian in a private communication: “. . . there would be advantages in being on the ground floor."

From discussions, we noted that the latitudinal location of Odense in relation to the 
North Pole and the strong winds that were a feature of the Coleraine climate to a large extent influenced these institutions in their choice of a spine design model: apart from ensuring the proximity of buildings to one another, it also protected staff and students from exposure to inclement weather.

\section{The COMMITteE's RePort}

In a subsequent report submitted to the University Council following the visits to Odense and Coleraine, the group wrote:

1. In neither library is the spine system operating effectively. In one case it is not in use at all; in the other it is minimally used. Where it is in use, institute (departmental) libraries still exist.

2. No evidence strongly in favor of a spine library was obtained; on the contrary, the central facilities actually operated at Coleraine were highly successful, functionally, administratively, and economically.

3 . The group therefore finds it difficult to recommend with any conviction the adoption of a spine library at Jos. . . . The group therefore concludes that, though the spine library should offer advantages compared with a system based on departmental libraries, the evidence it collected leads it to recommend that a central library be built.

\section{Conclusion}

It can be argued that the many advantages claimed for the linear library and listed earlier are so strong as not to make our observations at Odense and Coleraine lead to the rejection of the adoption of the spine library building model. However, it should be stated that three or so other factors have led us into shelving the plan. First was the almost unmanageable but expected length of the Jos University spine that would cover about 800 meters. Beyond that, the stipulation by the NUC banning the establishment of departmental libraries was a positive development.
Perhaps most important of all, the necessary technological base needed for the effective operation of a spine library was at the present lacking in our setting. In addition, the knowledge that the spine would remain a feature of the permanent site of the University of Jos precludes the future uncontrolled growth of the faculties that might isolate the users from a central library. Our new central library will be located close to the spine at a point roughly halfway along it: from it to any point on the campus will be no more than a ten-minute walk.

Two librarians operating spine libraries have this to say about them. Referring to it as the University of Cape Town's solution, Taylor went on, "I believe we are on to a good thing here and I think that it is also the best answer to many of the problems of university libraries that we have come across." Hurst of the New University of Ulster was also to state, "With hindsight, I have no regrets about what we have tried to do and if I had to start again, I would do more or less the same. ..."

My evaluation is that it is a model library for an institution that possesses the necessary technological base, is medium-sized, has no regulations discouraging both unplanned expansion and the establishment of departmental libraries, and, above all, is an institution whose library addresses positive and central involvement in its academic program.

Finally, the term spine library possesses a special appeal. Hitherto, the library has been figuratively described as the heart (physical as well as intellectual) of the university. However, if by remaining the heart it stands the possibility that the other members of the body far removed from it will tend to forget its existence, it may well be that the better simile should be the spine, no less important to the existence and working of the body, but stretched over a great deal of the mass of the body and closer to all its members.

REFERENCES

1. T. J. Galvin and A. Kent, "Use of a University Library Collection. A Progress Report on a Pittsburgh Study," Library Journal 102:2317-20 (Nov. 15, 1977).

2. "Editorial," Library Association Record 80:545 (Nov. 1978).
3. BALUCAL: The Bulletin and Accessions List of the University of Calabar Library 3 (May-June 1976).

4. Noel Savage, "News Report, 1978," Library Journal 104:155 (Jan. 15, 1979).

5. C. Achebe, "What Do African Intellectuals 
Read?" in his Morning yet on Creation Day: Essays (Exeter, N. H.: Heinemann, 1975).

6. An excerpt from a paper prepared by the director of planning, University of Jos, for the Council's Committee on the Incorporation of the Library on the Spine, Jan. 26, 1978.

7. L. E. Taylor, "The Linear Library: The University of Cape Town's Solution (1974)" (Paper read to the Western Cape Branch, SALA, Feb. $20,1974)$, p. 10.

8. Joel M. Lee to the author, March 2, 1978.

9. The New University of Ulster, "Report to the University Court, 1975-1976," p.30.

10. L. E. Taylor, "The Linear Library," p.11.
11. F. J. E. Hurst, "A New Library in Action" (Synopsis of a paper read at the INULS Conference, Galway, March 1976).

12. The New University of Ulster, "Report on the Development Plan, 1968," p.31.

13. L. E. Taylor, "The Linear Library," p.8.

14. Ibid.

15. University Grants Committee, "Capital Provision for University Libraries: Report of a Working Party" (London, H.M.S.O., 1976).

16. H. W. Dillon, "Organizing the Academic Library for Instruction," Journal of Academic Librarianship 1:4-7 (Sept. 1975). 